This item was submitted to Loughborough's Research Repository by the author.

Items in Figshare are protected by copyright, with all rights reserved, unless otherwise indicated.

\title{
Comparison of electrical and mechanical water pump performance in internal combustion engine
}

\section{PLEASE CITE THE PUBLISHED VERSION}

http://dx.doi.org/10.1504/IJVSMT.2015.070155

\section{PUBLISHER}

(C) Inderscience

\section{VERSION}

AM (Accepted Manuscript)

\section{PUBLISHER STATEMENT}

This work is made available according to the conditions of the Creative Commons Attribution-NonCommercialNoDerivatives 4.0 International (CC BY-NC-ND 4.0) licence. Full details of this licence are available at: https://creativecommons.org/licenses/by-nc-nd/4.0/

\section{LICENCE}

CC BY-NC-ND 4.0

\section{REPOSITORY RECORD}

Wang, Xu, Xingyu Liang, Zhiyong Hao, and Rui Chen. 2015. "Comparison of Electrical and Mechanical Water Pump Performance in Internal Combustion Engine”. figshare. https://hdl.handle.net/2134/16561. 
2014 Accepted version by Int. J. of Vehicle Systems Modelling and Testing

Comparison of Electrical and Mechanical Water Pump Performance in Internal

\title{
Combustion Engine
}

\author{
Xu Wang* \\ RMIT University, \\ Bundoora East, Vic 3083, Australia \\ Fax: +61-3-99256108100 \\ E-mail: xu.wang@rmit.edu.au \\ *Corresponding author \\ Xingyu Liang \\ State Key Laboratory of Engines, \\ Tianjin University, \\ 92\#, Weijin Road, Nankai District, \\ Tianjin 300072, China \\ E-mail: 1xy@tju.edu.cn
}

School of Aerospace, Mechanical and Manufacturing Engineering,

Zhiyong Hao

Department of Energy and Power Engineering

Zhejiang University

Hangzhou, P R China

haozy@zju.edu.cn 


\section{Rui Chen}

School of Aeronautical, Automotive, Chemical and Materials Engineering Loughborough University Loughborough, Leicestershire, LE11 3TU, UK e-mail: R.Chen@lboro.ac.uk

Keywords: Power; Torque; Electrical Water Pump; Mechanical Water Pump.

Reference to this paper should be made as follows: Wang, X., Liang, X., Hao, Z. and Chen, R. (2015) 'Comparison of Electrical and Mechanical Water Pump Performance in Internal Combustion Engine', International Journal of Vehicle Systems Modelling and Testing, Vol. XX, Nos. XX, pp.XX-XX.

Biographical notes: $\mathrm{Xu}$ Wang received his $\mathrm{BE}$ (Hons) and MS in Internal Combustion Engine from Tianjin University, China, in 1985 and 1989, respectively, and his $\mathrm{PhD}$ in Mechanical Noise and Vibration from Monash University, Australia, in 1994. He is currently an Associate Professor in Automotive Engineering, at RMIT University, Australia. He is Fellow of Society of Automotive Engineers, Director of Society of Automotive Engineers, Australiasia. His research interests include the areas of vehicle design, development and manufacturing, noise and vibration control, design and construction of robots and manufacturing plants, material engineering, internal combustion engine, etc. 
Xingyu Liang is an Associate Professor at State Key Laboratory of Engines, Tianjin University, China.

Zhiyong Hao is a Professor at Department of Energy and Power Engineering, Zhejiang University, China.

Rui Chen is a Professor at School of Aeronautical, Automotive, Chemical and Materials Engineering, Loughborough University, UK.

\begin{abstract}
This paper illustrates the differences between mechanical and electrical water pumps of internal combustion engine. Literatures have been studied in regard to engine cooling with the water pumps. Main design features of the mechanical and electrical water pumps have been illustrated. Engine dyno tests have been carried to evaluate if increased torque and power can be obtained in a common internal combustion engine (ICE) fitted with an electric water pump. Experiments were conducted to verify the effectiveness of an electrical pump over a standard mechanical pump.
\end{abstract}

Keywords: Power; Torque; Electrical Water Pump; Mechanical Water Pump; Oil Temperature; Water Temperature, Cylinder Wall Temperature.

\title{
1. Introduction
}

Since the invention of internal combustion engine in 1883, the process of combustion unfortunately produces an abundance of waste heat energy which needs to be removed in a 
systematic manner via a cooling system to prevent damage to any mechanical components. The output of the energy as a percentage of the energy generated by the fuel in the combustion process is shown in Figure 1 for a modern passenger car engine when tested through a "NEDC ECE 15 EUDC" European drive cycle. Specifically, the energy generated has $13 \%$ exhaust heat losses to the wall and $18 \%$ wall heat losses which needs to be removed by a transfer mechanism to lower the engine's temperature [Zoz, S., Thelen, W. , Alcenius, T. and Wiseman, M., 2001]. Hence in this case the heat transfer medium is the coolant fluid circulated by a water pump in the engine's cooling system.

Output energy as a percentage of the energy generated by the fuel in a passenger car engine

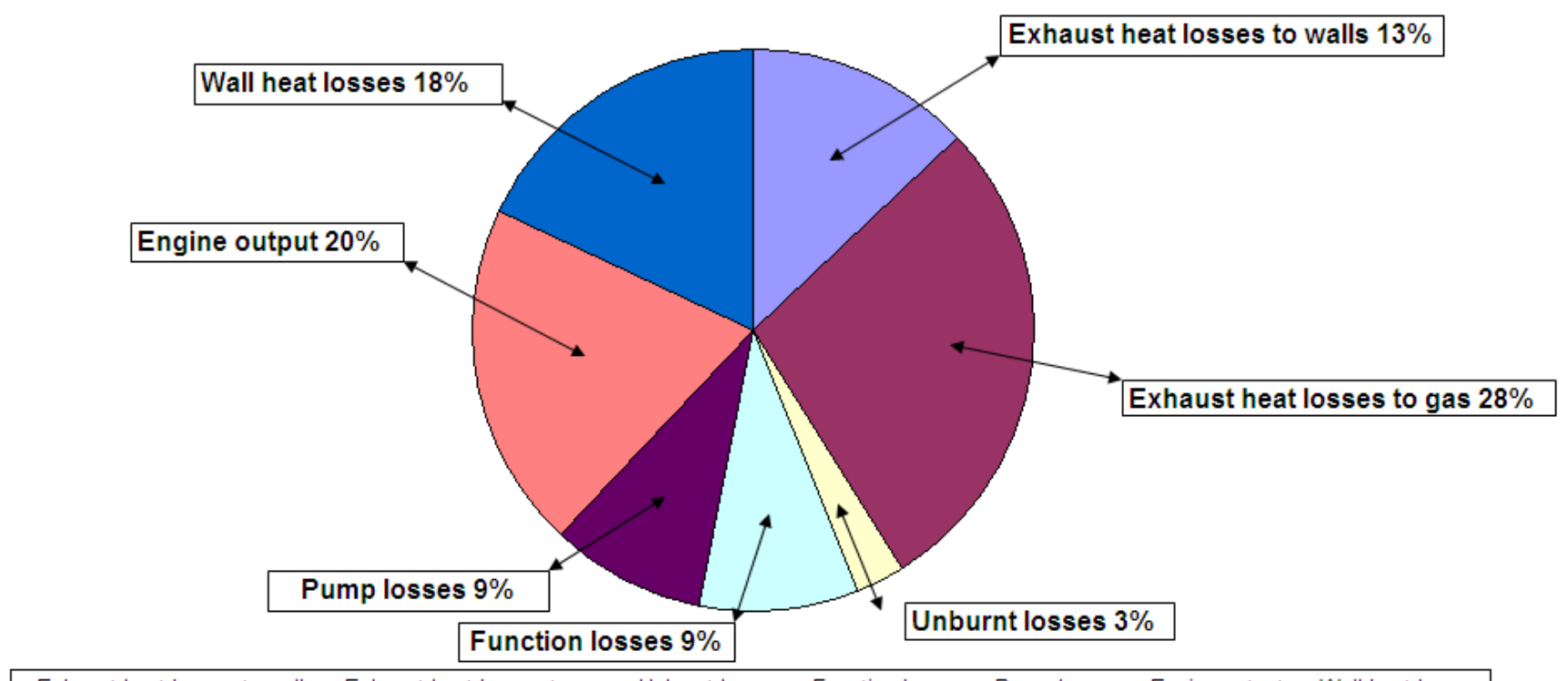

$\square$ Exhaust heat losses to walls $\square$ Exhaust heat losses to gas $\square$ Unburnt losses $\square$ Function losses $\square$ Pump losses $\square$ Engine output $\square$ Wall heat losses

Figure 1 Output energy as a percentage of the energy generated by the fuel in a modern passenger car engine tested in a "NEDC ECE 15 EUDC" European drive cycle [Zoz, S. , Thelen, W. , Alcenius, T. and Wiseman, M., 2001].

When the engine power output is substantially increased, the large amount of heat generated needs to be removed in a timely manner to prevent damage to the engine components. In this case, the coolant fluid, marked in a blue colour as shown in Figure 2, is required to circulate around an engine to sufficiently carry the heat away, not only from the combustion chamber but also other critical areas of the engine such as the engine block, the cylinder head, the radiator and the heater core as demonstrated in Figure 2. It is this movement and circulation of 
the coolant fluid that is studied in this paper. Hence, the water pump can be either mechanically or electrically driven to circulate the coolant fluid around the engine in this cooling system. Instead of use of water, the coolant is often mixed with water in modern vehicle engines, which prevents the coolant fluid from either freezing or boiling, because the freezing or boiling water will significantly reduce the effectiveness of heat removal.

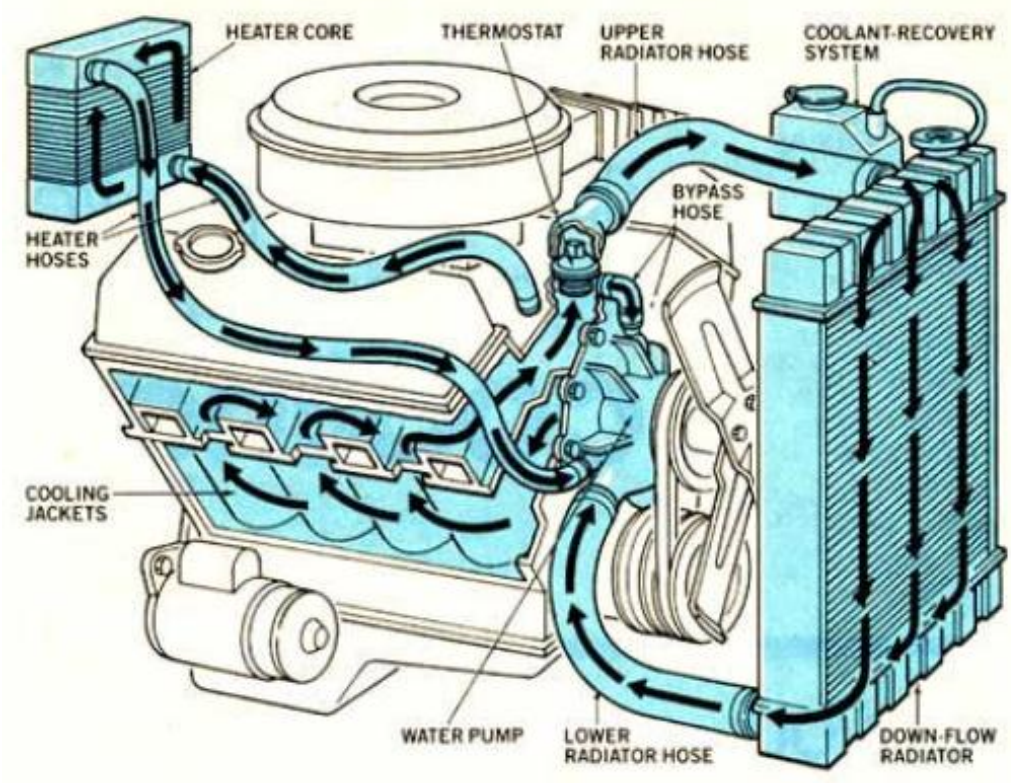

Figure 2 Water cooling engine cylinder head.

The water pump has been improved in line with the internal combustion engine, and so has been optimized in terms of its reliability and performance. In its current state in many models of vehicles it is built to be cost effective and able to meet the demands of the engine under light to heavy loads. Presently, single stage radial centrifugal pumps are used in the vast majority of motor vehicle cooling circuits [Van Basshuysen, R. and Schafer, F., 2007]. The speed of the pump and coolant flow rate are linked directly to the engine speed, through a serpentine belt or meshing gear running directly off the engine's crankshaft, running at a specific transmission ratio. The specific ratio, as well as the pump impeller pitch and general design, are specified in order to protect the engine under high load conditions, for example hill climbing, towing or driving in atmospheres with high ambient temperatures, or all of the conditions combined. The major problem with the mechanical water pump is that its design has missed the process control where 
the coolant fluid pump should be controlled via demand orientated controllers and not mechanically linked. In simple terms a demand orientated controller should use a manipulated variable, in this case, impeller speed, to handle the controlled variable, coolant fluid temperature.

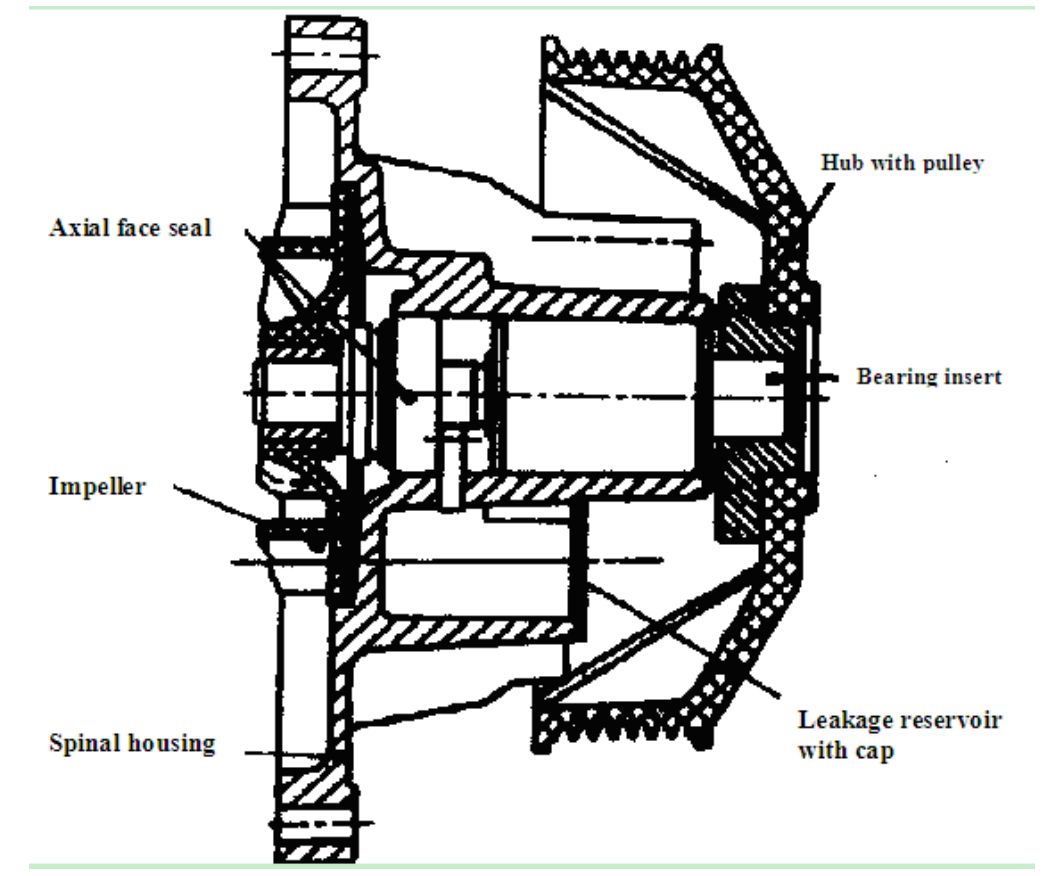

Figure 3 Cross section of a typical mechanical water pump.

As seen in Figure 3, a typical mechanical water pump consists of an impeller located inside spiral housing and sealed via an axial face seal. The spiral housing is mounted against the engine block with channels leading in and out of the coolant fluid channels within the engine block. The mechanical power arrives via the hub with pulley. The channels on the pulley indicate the interface for the guides on the serpentine belt which transmits power from the crankshaft. Either driven by an accessory drive belt or meshing gears, the mechanical water pump is designed to circulate the coolant fluid through the engine based on the engine speeds. The drive on a standard pump links the pump rotational speeds, the coolant flow rate to the engine rpm [Allen, D. J. and Lasecki, M. P., 2001]. Due to this physical connection to the engine speed, many studies show that a conventional mechanical water pump produces the correct amount of coolant flow for only a $5 \%$ of the time or only at high loads and ambient temperatures where it requires the maximum pump flow rate. As the mechanical water pump is the setup with a specific drive ratio and 
impeller suited for the highest or full load conditions at an engine speed, it is common for the impeller to run the same speed unnecessary during a part load regular engine operation.

Also, at the speeds, higher than the rated engine speeds, the head, flow rate and hydraulic efficiency of the mechanical water pump fall considerably [McCabe, W. L., Smith, J. C. and Harriott, P., 1993]. At the speeds higher than the rated engine speeds, theoretical head capacity, often called the head capacity relation, drops linearly with increased flow rate due to increased circulatory flow and frictional losses. The actual head capacity drops much more severely due to the losses in real situations. However it is common for vehicle engine to be run above the rated or optimum speed [McCabe, W. L., Smith, J. C. and Harriott, P., 1993] where the coolant fluid flow friction and shock losses convert the mechanical energy into heat. Leakage, disk friction and bearing losses all contribute to the difference between actual power and theoretical power for the working coolant fluid transfer. Therefore, beyond the rated or optimum flow rate, the hydraulic power decreases [McCabe, W. L., Smith, J. C. and Harriott, P., 1993]. The ratio of hydraulic power to the total power input rises rapidly at low rates, reaches a maximum and then falls in line with the flow rate as it approaches the zero head, the maximum flow rate the pump can deliver under any conditions [McCabe, W. L., Smith, J. C. and Harriott, P., 1993]. The mechanical water pump efficiency falls at the increased flow rates after the rated or optimum flow rate is reached [McCabe, W. L., Smith, J. C. and Harriott, P., 1993].

As the automotive industry strives to develop cleaner burning and more fuel efficient engines, an electric water pump is becoming a sensible alternative to its mechanical counterpart. Modern vehicles, in particular, the hybrid electric vehicles, have adopted advanced electronically control systems and sensors which have impacts on the engine cooling system, because negative aspects of the mechanically driven water pump are possible to be avoided [Allen, D. J. and 
Lasecki, M. P., 2001]. Since the coolant flow rates of the mechanical water pumps are related to the engine speeds [Wagner, J. R., et al., 2002], the thermal control using the mechanical water pumps is generally not effective [Robert, D. and Chalgren, Jr., 2004] \& [Haipeng, L. and Figliola, R. S., 2004]. An electric water pump shall be a good alternative to the current mechanical water pump, as the electric water pump may have an opportunity to remove a source of parasitic loss from the internal combustion engine and provide a better control of the engine temperature according to the engine heating and cooling requirements [Kluger, M. and Harris, J., 2007] \& [AP, N. S. and Golm, N. C., 1997] \& [Choukroun, A. and Chanfreau, Matthieu, 2001].

Since an electric pump offers an effective flow control capability which is totally independent of engine speeds, this can lower the system operating requirement with a reduced pump flow rate at high engine speeds. This allows the engine to run at a more steady temperature, as there is no sudden fluctuation in the coolant flow rate [Jawad, et al, 2004]. Some advantages of an electric water pump used in internal combustion engines are discussed as below:

1. Design Losses - mechanical water pumps must be mounted where the power to drive them is available. The power is usually at the front of the engine where belts or gear-train can be used to provide the drive power. In some instances, this package constraint can limit the ability to design a pump system and result in a reduced head flow. Furthermore, the mechanical pump design has performance limiting characteristics such as fluid cavitations and erosion [Allen, D. J. and Lasecki, M. P., 2001]. An electric pump can be remotely mounted, allowing the flow characteristics to be hydraulically optimized while not impacting on the design constraint of both the overall engine installation package and the cooling system effectiveness [Ribiero, E. G., 2007].

2. Drive Losses - the gear drives of the mechanical water pump place large accelerations into the pump shaft due to the gear teeth mesh which generates high cyclic side 
loads on the pump bearings. The belt driven water pumps do not have the same accelerations as the gear driven ones, but the belt driven water pumps can experience larger side loads due to the drive belt tension. Both of these 'driving' factors require the mechanical water pumps to have large bearings and the physical design to support the bearing loads. Electrical pumps feature a drive motor in line with the impeller eliminating the need for large bearings and in some cases seals depending on the type of coupling used between the motor and pump which further reduces the pump drag friction loss [AP, N. S. and Golm, N. C., 1997].

3. Operating Losses - mechanical water pumps deliver the coolant flow and pressure directly proportionally to engine speed, the only means of adjusting the coolant flow rate and pressure is through use of the restriction valves. On the other hand, an electric pump can operate as a function of the engine cooling requirement(s) which can adjust coolant flow rate based on 'need', not engine speed [Choukroun, A. and Chanfreau, Matthieu, 2001].

4. Eliminate Hot Soak after Shutdown - an electric pump is able to circulate coolant fluid throughout the engine post shutdown which enables one to control the engine's thermal mass to prevent the overheat of critical components. This feature may also allow for design of engines operating at higher temperatures considering that the hot soak design limits will be eliminated [Ribiero, E. G., 2007] \& [Koga, Y., 2006].

Although mechanical water pumps or electric water pumps were studied in a lot of literatures, none of the literatures was to compare the both for the key performance index and characteristics in the same internal combustion engine. The objectives of this paper are to back to back compare an electrical water pump with a mechanical pump installed in a laboratory engine with a dynamometer for main engine performances and to verify the effectiveness of the electrical water pump over the standard mechanical water pump. In order to achieve those objectives, water pumps are first studied for their fundamental designs as below. 


\section{Design of water pumps}

A 3-D CAD model of a mechanical water pump used in the engine dyno test is shown in Figure 4. This CAD model can be used as a geometry data input to a CFD (computational fluid dynamics) software model to obtain the CFD results.

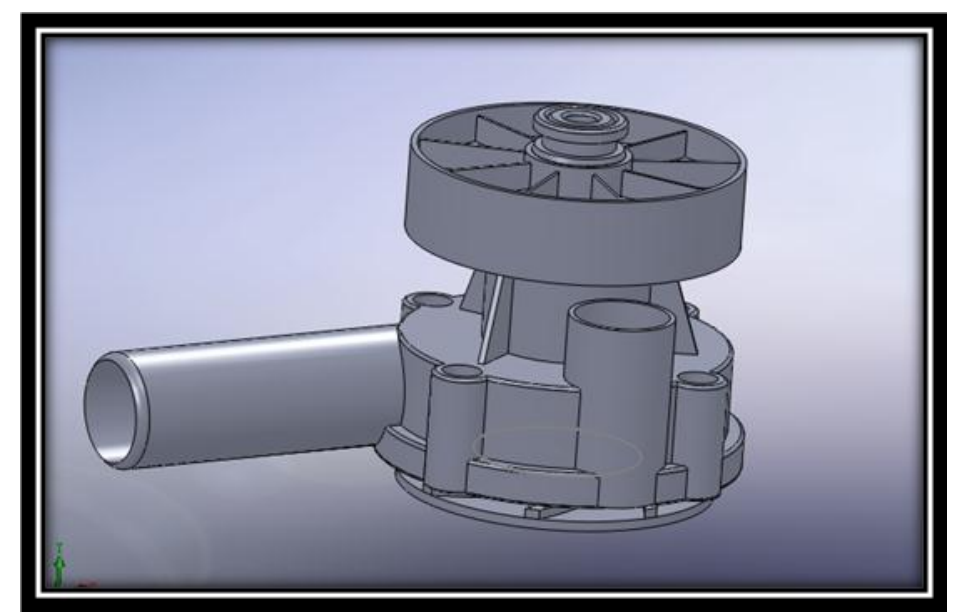

Figure 4 A CAD model of mechanical water pump.

The specific engine rotational speed can be calculated from the pump speed, discharge head and flow rate as [Karassik, I. J., et al., 2001]:

$$
N_{s}=\frac{N \sqrt{Q}}{H^{0.75}}
$$

where $\mathrm{N}_{\mathrm{s}}$ is the specific engine speed in rpm; $\mathrm{N}$ is the pump rotational speed in rpm, $\mathrm{H}$ is the discharge head and $\mathrm{Q}$ is the fluid mass flow rate. If the ratio of the crank pulley over the water pump pulley is 2 . Hence, the pump speed is 2 times of engine speed. With the flow rate, we can calculate discharge head, the fluid horse power and the fluid inlet velocity, which will be used in the following CFD analysis. The head coefficient can be written as

$$
\Psi=\frac{2 g H}{U_{2}^{2}}=2 \mu \eta_{h}\left[1-\frac{C_{m 3}}{U_{2}} \cot \left(\beta_{2}\right)\right]
$$


where $\Psi$ is the head coefficient or shut off constant; $g$ is the gravity acceleration; $\eta_{\mathrm{h}}$ is the hydraulic efficiency; $C_{m 3}$ is the meridian velocity; $U_{2}$ is impeller peripheral speed; $\beta_{2}$ is the discharge vane angle; the slip factor $\mu$ is given by

$\mu=\frac{C_{u 3}^{\prime}}{C_{u 3}}=1-\frac{\pi^{*} \sin \left(\beta_{2}\right)}{Z}$

where $\mathrm{C}_{\mathrm{u} 3}$ is theoretical peripheral velocity; $\mathrm{C}_{\mathrm{u} 3}{ }$ is the actual fluid peripheral velocity; $\mathrm{Z}$ is the number of blades. The meridian velocity is used to set inlet velocity for the Gambit software, and impeller peripheral speed is used for calculating the shut off point for the plotted pump curves in Figure 5. Given the head coefficient, the required impeller tip speed can be calculated by:

$$
U_{2}=\sqrt{\frac{2 g H}{\Psi}}
$$

A 2D water pump geometry was drafted by a CAD software; the pre-processing software Gambit was then used to generate mesh and define the boundary condition. After meshing the geometry, the post-processing software Fluent 6 was used to calculate the pressure rises for different pump flow rates from the above parameter inputs. The results of pressure rises versus the pump flow rates are plotted in Figure 5 for the engine speeds of $2000 \sim 5000 \mathrm{rpm}$. It is seen from Figure 5 that different engine speeds will have different water pump performance curves; as the flow rate increases, the pump head decreases.

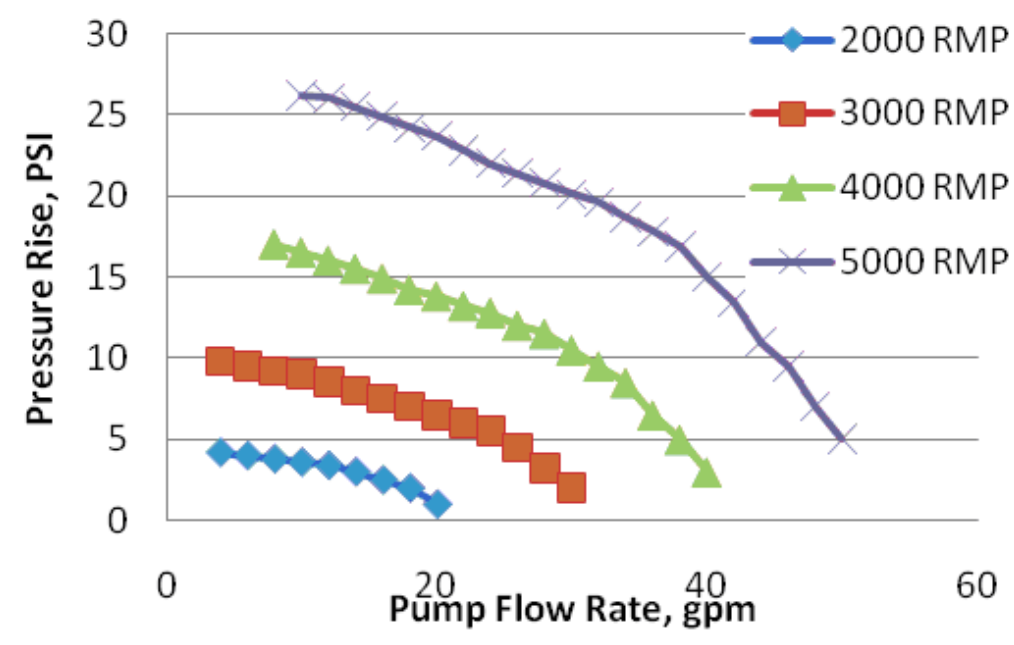


Figure 5 mechanical water pump performance

In the same way, the hydraulic efficiency of the mechanical water pump can be calculated and given in Figure 6. It can be seen from Figure 6 that for each of the engine speeds, the hydraulic efficiency first increases as the pump flow rate increases, then reaches a maximum value, finally decreases as the pump flow rate increases. The maximum hydraulic efficiency value for each of the hydraulic efficiency curve for each of the engine speeds is recorded in Table 1.

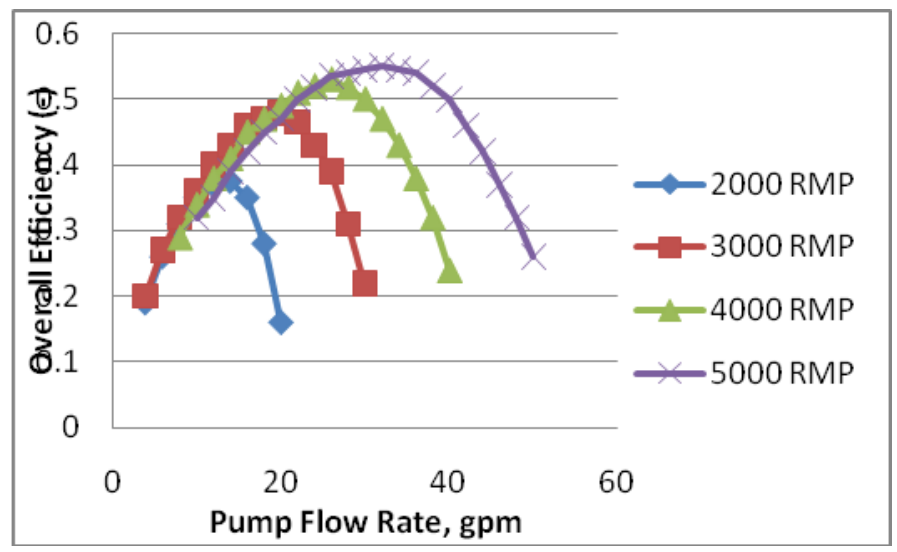

Figure 6 mechanical water pump efficiency.

The fluid horse power can be calculated by multiplying the flow rate with the total discharge head. If the ratio of the crank pulley over the water pump pulley is assumed to be 2 for the mechanical water pump, for example, the fluid horse power can be calculated from the X-Y data at each of the points on one of the curves in Figure 5 for each of the engine speeds. The water pump input powers for different engine speeds can be calculated from the fluid horse powers divided by the maximum hydraulic efficiency values listed in Table 1 .

Table 1 The variation of best efficiency and input power for different engine speeds.

\begin{tabular}{|c|c|c|}
\hline $\begin{array}{c}\text { Engine speed } \\
\text { (RPM) }\end{array}$ & Best efficiency & Input power (kW) \\
\hline 2000 & $37.5 \%$ & 0.185 \\
\hline 3000 & $48 \%$ & 0.183 \\
\hline 4000 & $53 \%$ & 0.198 \\
\hline 5000 & $55 \%$ & 0.219 \\
\hline
\end{tabular}


It is seen from Table 1 that at $5000 \mathrm{rpm}$, the mechanical water pump shows the highest best efficiency and input power, which are $55 \%$ and $0.219 \mathrm{~kW}$, respectively. Accordingly, at this speed, the fuel consumption will be the highest as well.

A development electric water pump will be tested in the engine dynamometer in a comparison with the benchmark mechanical water pump. The technical specifications of electric water pump are given in Figure 7, and the electric water pump performance curve is given in Figure 8 where the vertical axis represents the pressure rise, the horizontal axis represents the flow rate. It is seen that when the pump flow rate increases, the pressure rise decreases. The performance curve of the development electric water pump has the same trend as those curves in Figure 5, but differently, it is independent of the engine speeds.

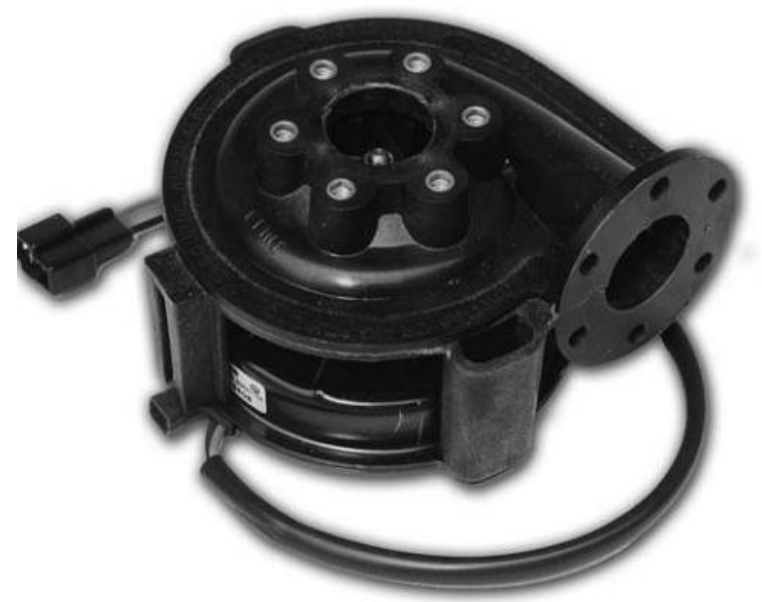

Technical Specifications

\begin{tabular}{|c|c|}
\hline Operating Voltage & $4 \mathrm{~V} \mathrm{DC}$ to $14.5 \mathrm{~V} \mathrm{DC}$ \\
\hline Maximum Current & 7.5 Amps \\
\hline Fowrate (Max.) (@ 13.5V DC & $80 \mathrm{~L} / \mathrm{min} .(1300 \mathrm{US} \mathrm{gal} / \mathrm{hr})$ \\
\hline Operating Temperature & -20 to $130 \mathrm{DegC}$ \\
\hline Pump Design & Clockwise Centrifugal \\
\hline Motor Life & 2000 hours at $80 \mathrm{Deg} C$ \\
\hline Pump Weight & 900 grams $(2.0 \mathrm{lb})$ \\
\hline Pump Material & Nylon $66,30 \%$ Glass Filled \\
\hline Max. Radiator Cap Pressure & $200 \mathrm{Kpa} \mathrm{(29} \mathrm{psi)}$ \\
\hline Seal & Ceramic Mech Face Seal \\
\hline Fits Hose Sizes & 32 to $51 \mathrm{~mm}$ ( $11 / 4$ to 2 ins) \\
\hline Fuse Rating & $10 \mathrm{Amp}$ \\
\hline
\end{tabular}

Figure 7 technical specifications of the development electric water pump [Davies Craig Catalogue, 2010].

It is seen from Figures 7 and 8 that at the best efficiency point, the input power of electric water pump is $7.5 \mathrm{~A} * 13.5 \mathrm{~V}=101.25 \mathrm{w}=0.10125 \mathrm{kw}$. This means the electric water pump consums much less energy or fuel than the mechanical water pump in a comparison with the data in Table 1. 


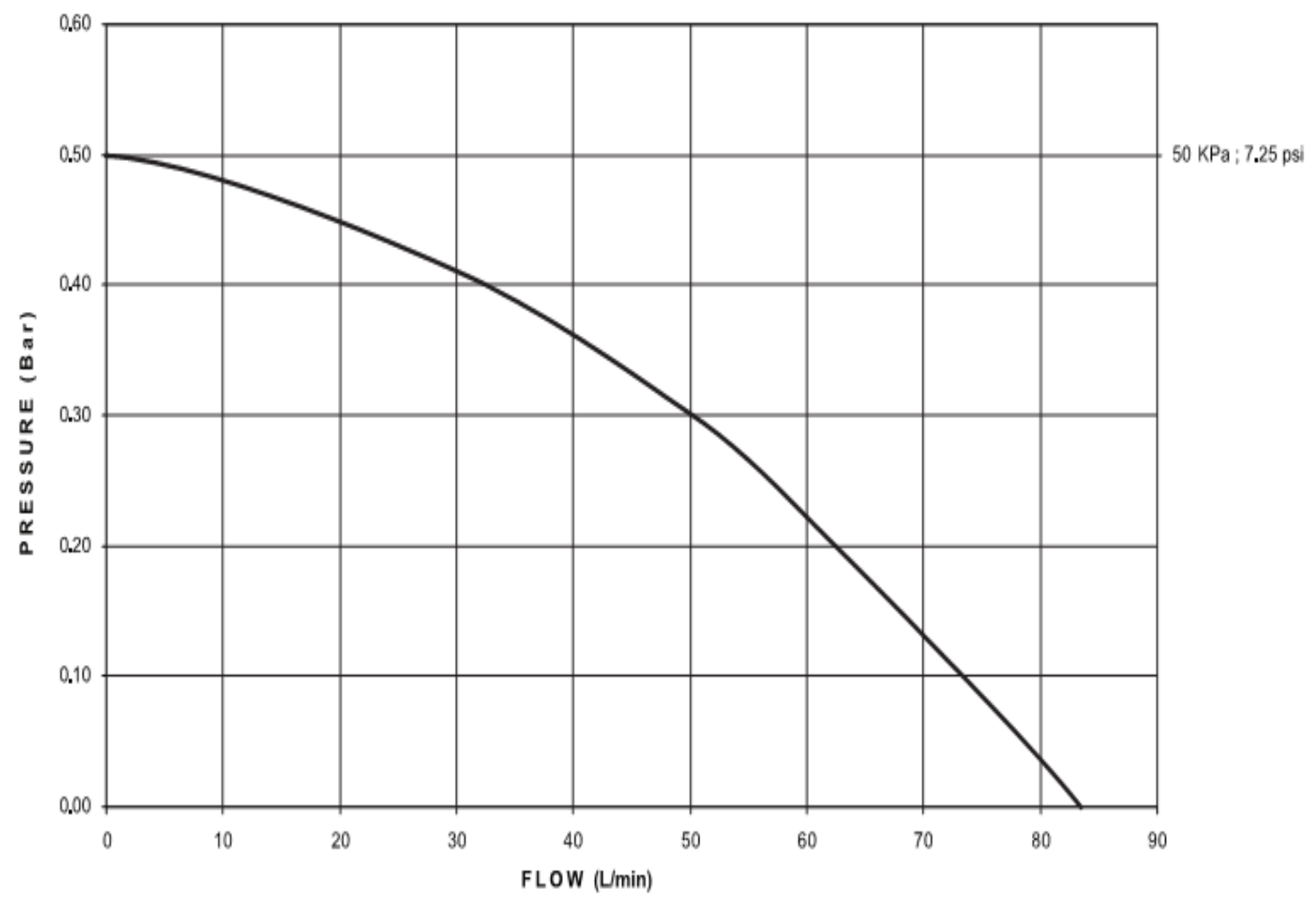

Figure 8 Electric water pump performance [Davies Craig Catalogue, 2010]

The materials of the pump housing of the mechanical water pump are usually aluminium or gray cast iron. The material of the pump housing of the electric water pump can be nylon 66 (30\% glass fibre filled), aluminium, nylon, plastics and gray cast iron for some of the parts [Allen, D. J. and Lasecki, M. P., 2001]. The material difference leads to a weight saving for the vehicle where the engine and the electric water pump are installed [Zoz, S., Thelen, W., Alcenius, T. and Wiseman, M., 2001].

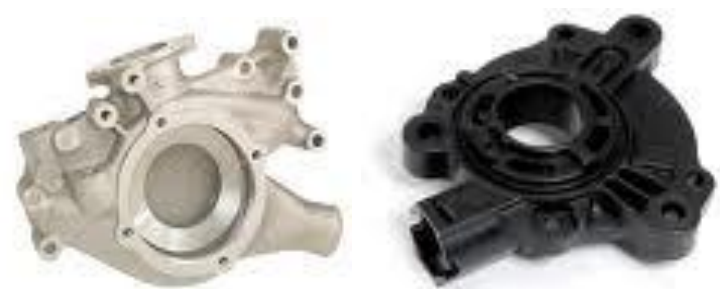

Figure 9 Materials for pump housing.

The materials of the pump impeller are usually duroplasts, thermalplasts, sheet metal, aluminium, which are used in passenger car and gray cast iron which is used in commercial vehicle as shown in Figure 9. Potential water pump impeller materials are titan-alloy, carbon-fibre and magnesiumalloy as shown in Figure 10. Ti-alloy is a very lightweight but expensive material, and currently 
is not affordable. The advantages of carbon fibre are low density, high tensile strength and low thermal expansion. In addition, it is strong when stretched or bent, while weak when compressed or exposed to high shock. The carbon fibre is currently having difficulties for a mass production. Magnesium-alloy has excellent damping capacity, good heat dissipation, high castability and excellent machinability. Compromising the cost and the characteristics of the above materials, the Magnesium-alloy is relatively good to be selected as the future material for the electric water pump impellers.

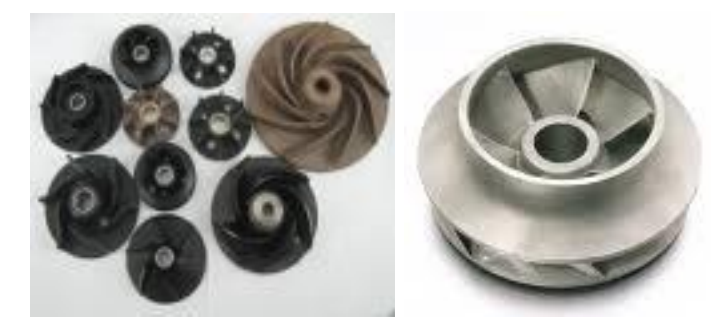

Figure 10 water pump impellers.

The manufacturing techniques of the mechanical water pump include casting, forging, machining, assembly of the water pump and inspection. Machining the mechanical water pump involves $\mathrm{CNC}$ turning, pin boring, grinding the side face, milling of housing and machining impeller and pulley. An electric water pump is much simpler to manufacture than its mechanical counterpart, as the total number of parts of the electric water pump is much less. The pump housing can be made from thermal/injection moulding and machining processes, while the impeller can be made from casting and machining processes.

Design failure mode and effect analysis (DFMEA) has been conducted for the electric water pump. One of the major risks associated with the electric water pump could be the electric motor burnout due to an impurity getting caught in the impeller and stopping the pump. For a regular mechanical water pump, such a blockage would result in belt slippage and cause no major issues with the pump itself. However with a direct linkage to a motor shaft in the electric water pump, such a blockage would result in a burnout of the motor. To countermeasure this issue it is 
recommended to use coolant fluid filters. A CFD analysis is performed to find the optimum design to not allow the blockage whilst still maintaining required performance or a fuse in the electric circuits may be used to protect the motor from an overload. One common method being adopted by pump suppliers is to use a magnetic drive, whereby the pump is driven by magnetic force through the pump housing. This has the added benefit for removing a flange / gasket and potential source of coolant fluid leakage.

\section{Engine dynamometer tests for the water pumps}

In order to verify the effectiveness of an electrical pump over a standard mechanical pump, engine dynamometer tests have been conducted where the engine fitted with the mechanical and electric water pumps was run back to back. The two tests were:

1. Power and torque test across the RPM range

2. Cool down time / Heat Soak reduction test.

Furthermore, the dynamometer tests were also set up to record various engine temperatures at each engine speed point to monitor any temperature changes.

As shown in Figures 11 and 12, the engine test facility is a $600 \mathrm{~kW}$ Power Masta engine dynamometer connected to one computer which controls the engine dynamometer's torque and its threshold setting along with six data acquisition channels to record various temperatures via thermocouples. In addition, another computer is installed with the MOTEC engine software package, which acts as the test engine control computer. Two mechanical pumps were used in the tests. One is a standard mechanical pump which is an "attached type" with a simple impeller consisting of 10 folded metal blades. The pump uses a hub with pulley, driven through a serpentine belt which is run from the crankshaft. The other is a modified mechanical pump with 
the impellor machined off to maintain the drive shaft and bearings in order to avoid coolant fluid leakage and to pass the coolant fluid freely through the engine. Hence, when the electric water pump is fitted, the standard mechanical water pump is replaced with the modified pump to allow the coolant fluid to flow through the engine as pumped by the electric water pump. The power required to drive the hub would obviously be reduced and neglected. The development electric pump was mounted in series between the engine and radiator core, that is, between the coolant fluid outlet of the dynamometer cell's radiator tank and the coolant fluid inlet side of the test engine as shown in Figure 13. The electric water pump power switch was placed in the Dynamometer control area in order that it could be switched on and off as required by the operator.

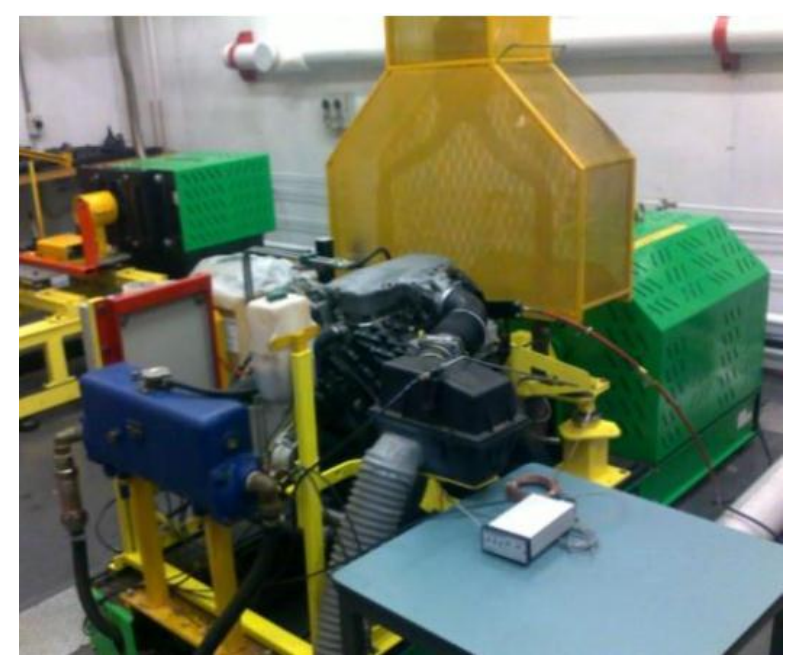

Figure 11 engine dynamometer.

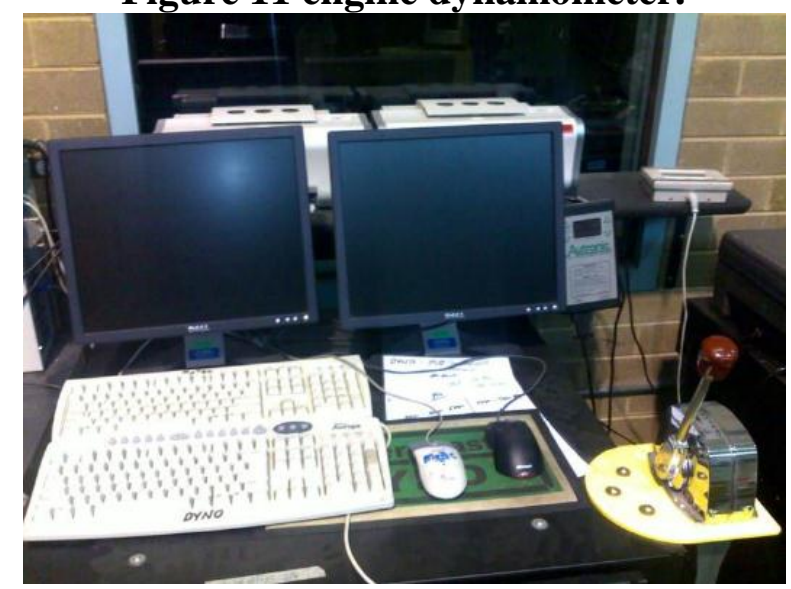

Figure 12 Computers for the engine control and data acquisition. 
The test engine as shown in Figure 11, is a 3.8L V6 as used in many locally produced vehicles. The engine specifications are listed in Table 2. The engine's block and cylinder heads are built of cast iron and joined to an aluminium intake manifold and timing cover with a front mounted water pump.

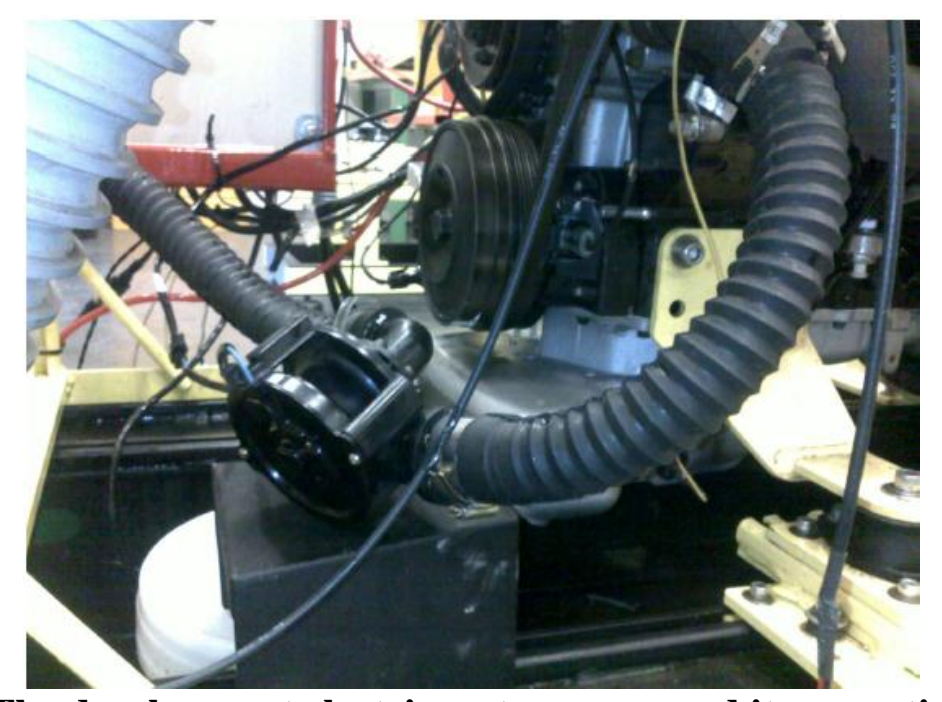

Figure 13 The development electric water pump and its mounting position.

In order to monitor the engine's behaviour, the engine was instrumented with six individual thermocouples, in addition, the engine heating and cooling time were recorded, when the electric water pump was turned on or off. Since two computers were required, the computer's clocks were synchronised before running the tests. Once all the tests were completed, data logging stopped at the same time. The six thermocouple positions are listed in Table 3.

Table 2 The test engine specifications

\begin{tabular}{|c|c|}
\hline Capacity & $3.8 \mathrm{~L} \mathrm{V6}(\mathrm{L} 36)$ \\
\hline Stroke & $86 \mathrm{~mm}$ \\
\hline Bore & $97 \mathrm{~mm}$ \\
\hline Power & $205 \mathrm{hp} / 153 \mathrm{~kW}$ \\
\hline Torque & $230 \mathrm{lb} / \mathrm{ft} / 312 \mathrm{~N}^{*} \mathrm{~m}$ \\
\hline Overall weight & $178 \mathrm{~kg}$ \\
\hline
\end{tabular}

Table 3 Measurement temperatures at the locations of the six thermocouples

\begin{tabular}{|c|c|}
\hline Number & Temperatures at the locations \\
\hline $\mathbf{1}$ & Water temperature - before thermostat \\
\hline $\mathbf{2}$ & Water temperature - after thermostat \\
\hline $\mathbf{3}$ & Engine oil temperature \\
\hline $\mathbf{4}$ & Radiator tank temperature \\
\hline $\mathbf{5}$ & $\begin{array}{c}\text { Another Water Temperature - after } \\
\text { thermostat }\end{array}$ \\
\hline $\mathbf{6}$ & Dynamometer cell temperature \\
\hline
\end{tabular}


Power run tests were scheduled with a couple of cool down times in between. The mechanical water pump was first tested. The engine was started and run at idle until the oil temp reached above $60^{\circ} \mathrm{C}$. The dynamometer controller was set at the desired speed points of 2000, 2500, 3000, 3500, 4000 and 5200 rpm. The engine was throttled to about $75 \%$ load at the test speed points each by each. From there the engine was tested at about $75 \%$ load across the RPM range. Torque was recorded continuously and average values were used. Power was then calculated from the engine speeds and torque values. Engine torque, power and temperatures were recorded for all the speed points. The engine was switched off and allowed to cool for a period of 20 minutes observing the water temperature at 2 minute interval, which allows for observing whether the heat soak occurred and for experiencing how an engine usually cools down. In order to record the cool down time for the engine with mechanical water pump, the engine was started and run at idle until the oil temp stabilised, the engine was switched off, the temperature readings of each thermocouple were recorded for 20 minutes. After the tests of the mechanical water pump were completed, the mechanical water pump was replaced by the 'dummy' mechanical water pump with the impeller machined off, the electric water pump was installed to pump the coolant fluid through the hoses as shown in Figure 13. The above test procedures for the mechanical water pump were repeated for the electric water pump. After the engine tests with the electric water pump were completed, the engine was switched off for a 20 minute cooling period. The engine was started again and run at idle until the oil temp stabilised, the engine was switched off, the electric water pump was allowed to keep running for 20 minutes to investigate the impact of continued coolant flow on the heat soak.

\section{Test results and discussions}

With the test schedule completed, all the results were compared for the performance of each water pump type. Figure 14 shows the powers and torques for the engine with the mechanical and electric water pumps. When the engine is equipped with an electric pump, the engine's torque output is approximately $2 \sim 4 \mathrm{~N}^{*} \mathrm{~m}$ higher than that with the mechanical pump at 
each engine speed recorded. This is indicated by the red and dark blue curves in Figure 14, for the mechanical and electrical pumps respectively. Since engine power is a function of the torque, the engine power follows the difference in the torque and therefore the engine with the electrical pump provides more power than that with the mechanical pump. When referring back to the assumption regarding improving the engines efficiency by utilising an electric water pump to reduce an engine's parasitic loss, the engine power enhancement with an electric pump is expected, although the effective engine cooling brought by the electric water pump may also result in increased frictional losses and power loss.
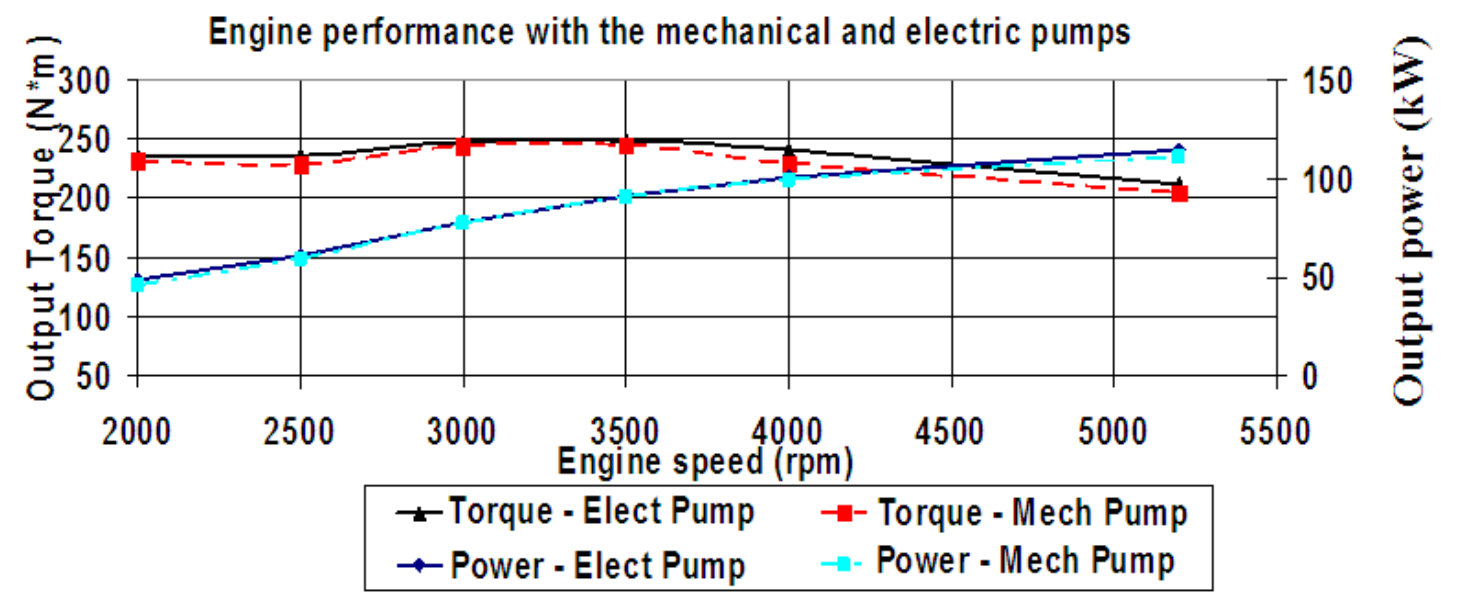

Figure 14 Output torques and powers for the engine with the mechanical and electric water pumps.

Water Temp Before Thermostat

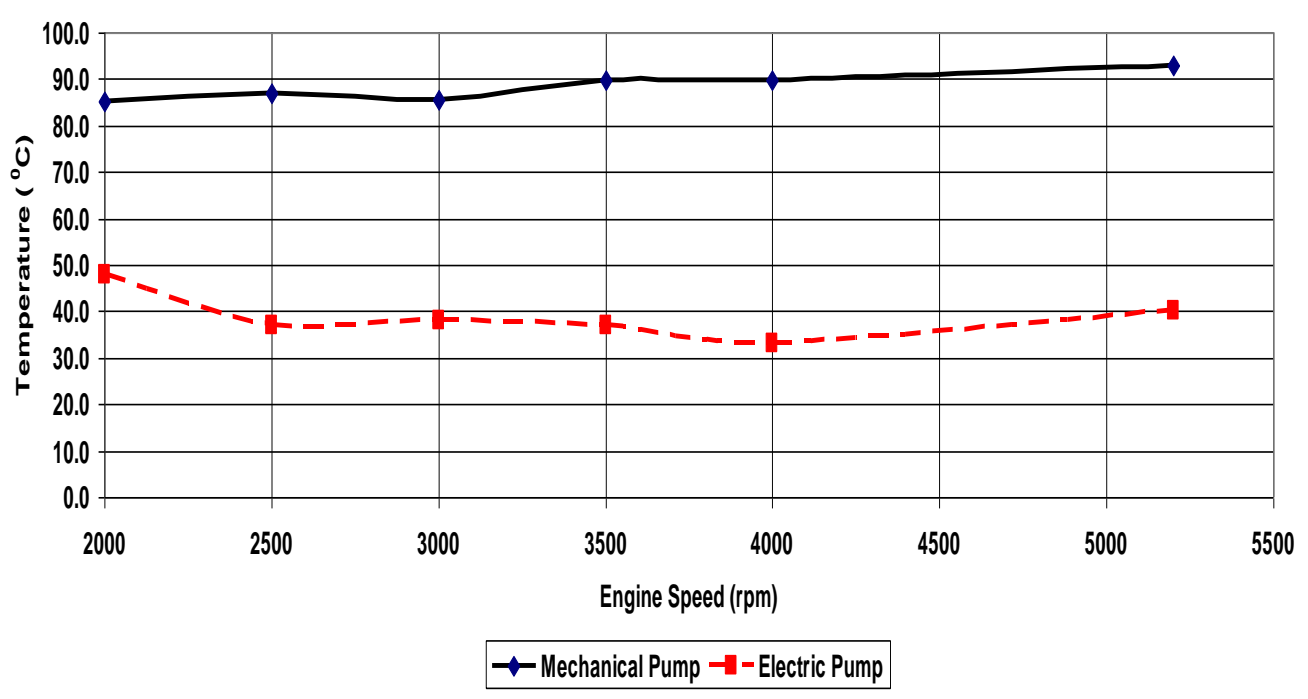




\section{Figure 15 Temperatures before the thermostat for the engine with the mechanical and}

electric water pumps.

Figure 15 shows the temperatures before the thermostat in the engine with the mechanical and electric water pumps. The chart clearly displays the dramatic effect which an electrical water pump can have on an engine's cooling system. Note that the dark blue curve, for the mechanical water pump slightly increases inline with engine speed where as the red curve for the electric water pump stays fairly stable and in fact, slightly decreases as engine speed increases. Figure 16 shows the oil temperature of the engine with the mechanical and electric water pumps. Once again, the electric water pump provides slightly cooler oil with a temperature by approximately $10^{\circ} \mathrm{C}$ less.

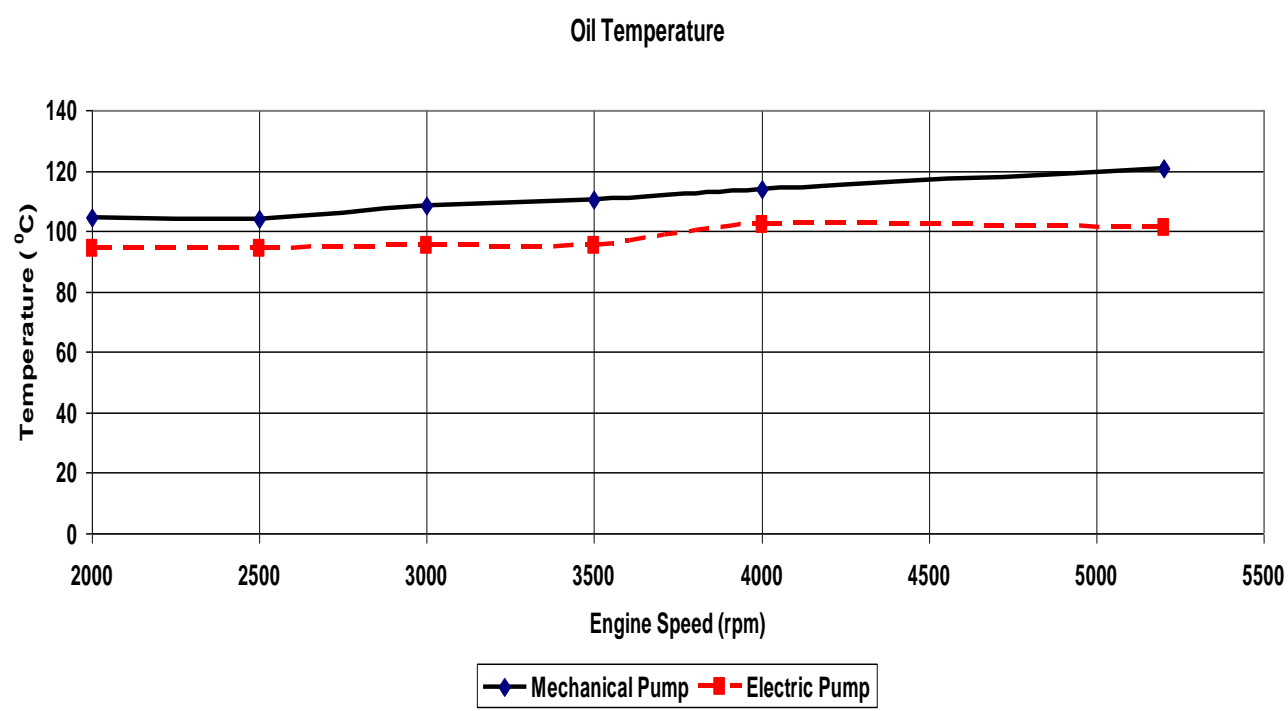

Figure 16 Oil temperatures for the engine with the mechanical and electric water pumps.

Closely related to the test engine's intake air charge temperature, the dynamometer cell ambient temperature was logged to ensure that the results are not skewed to favour one particular pump. If the dynamometer cell's temperature was hotter using one type of the pumps, the engine would then have to work harder to produce the same amount of power. Temperatures recorded for the engine dynamometer run with the two types of water pumps were very close. Referring to the other temperature and performance results, it was noted that this did not significantly skew the results. 
Once all the performance and temperature data was collected for each type of the water pumps, the time for engine cool down was measured, and the data shown in Figure 17. The engine oil temperatures of the two pumps are almost exactly the same since the engine oil was no longer circulated inside the engine when the engine was switched off. With respect to water temperatures, the data clearly demonstrates the rapidly cooling down effect which the electric water pump can have on the water temperature where the temperature decreased up to the ambient within 4 minutes from the engine being turned off. Running the electric water pump after the engine shutdown resulted in a significant temperature reduction within the first 4 minutes, after which the engine temperature became stable. The temperature reduction significantly reduces the risk of the heat soak and would therefore help to enhance the engine life and reliability. If the dark blue curve for the mechanical water pump water temperature is studied, it is clearly seen that the effect of 'heat soak' starts as the water temperature increases by at least $10^{\circ} \mathrm{C}$ from the engine being turned off, then slowly starts to cool down. This is because that the heat was left in the engine block and the coolant fluid after the engine was shut down. In reality, higher loads, speeds and ambient temperatures may result in larger heat soak, which explains why some vehicles have their engine cylinder heads damaged because of overheating.

\section{Cool down/Heat Soak Time}

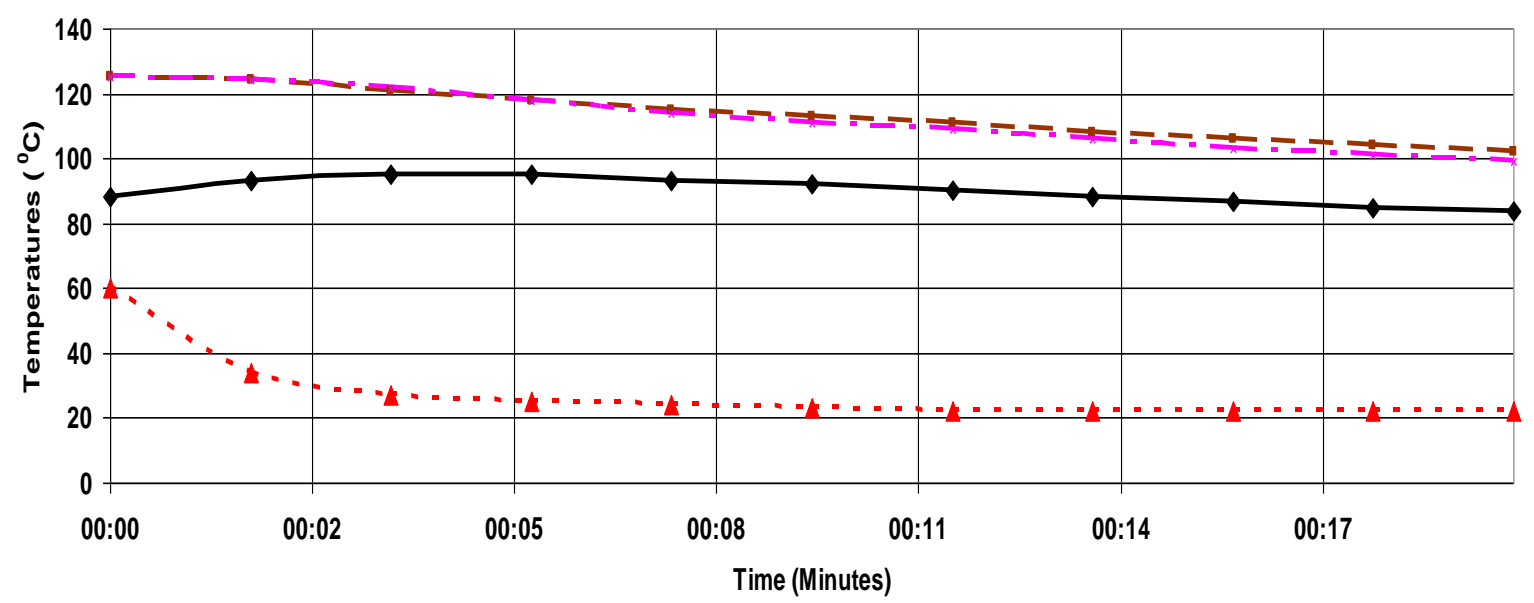

Water Temp - Mech $\rightarrow-$ Oil Temp - Mech - $\Delta$ - Water Temp - Electric $-x=$ Oil Temp - Electric

Figure $17 \mathrm{Cool}$ down/heat soak temperatures for the engine with the mechanical and electric water pumps. 
In a summary, the experimental analysis of mechanical and electrical water pumps for the engine performance has shown that the electrical pump outperformed the mechanical water pump. Understanding that the dynamometer cells ambient air temperatures were exactly the same for the pumps tested; the tests have not been skewed to favour one particular pump. Referring to the temperature results for the mechanical water pump vs. the electric water pump for the various temperature sensors it is clearly evident that some parts of the engine were run approximately $40 \%$ cooler with the electric water pump, for example, both the coolant fluid temperature and the engine oil temperature showed "cooler" values. As the electric water pump could pump more than adequate quantities regardless of engine speeds, the coolant fluid temperature was kept consistently low. With regards to the temperature performance, it is surely concluded that the electrical water pump is the clear winner. At every testing speed point recorded, the electrical pump outperformed the mechanical pump enabling the engine to run much cooler. One of additional tests performed in future for potential improvements should be, for example, to conduct an A-B-A-B test strategy, where the mechanical and electrical water pumps will be tested twice independently to ensure the results are both repeatable and reproducible. Hence, this will be a similar process to conduct the six sigma method of a "Gauge R\&R".

In order to further verify if the benefits are available for use of the electric water pump, it is necessary to adequately size the electric water pump and control its use via a proper understanding of the engine's optimum operation temperatures and then implement an ECU to manage the water pump switching to adequately control the engine temperature. Furthermore a variable speed electric motor could also increase controllability of the engine temperature at the optimum points. 


\section{Conclusions}

With regards to the engine performance enhancement and temperature reduction, the electric water pump well outperformed the mechanical water pump at every speed point. The benefits of the electric water pump in terms of torque, power and fuel consumption improvements will be realised with the detailed future development plans.

\section{References}

1. Allen, D. J. and Lasecki, M. P. (2001), Thermal Management Evolution and Controlled Coolant Flow, SAE Technical Paper Series 2001-01-1732.

2. Zoz, S., Thelen, W., Alcenius, T. and Wiseman, M. (2001), Validation of Methods for Rapid Design and Performance Prediction of Water Pumps, SAE 2001-01-1715.

3. Ribiero, E. G., (2007). Electric Water Pump for Engine Cooling, SAE Technical Paper 2007-012785 .

4. Koga, Y. (2006). Development for Stamped WATER PUMP (Innovative Structure WATER PUMP), SAE Technical Paper 2006-01-0615.

5. Jawad, B., Zellner, K. and Riedel, C., (2004), Small Engine Cooling and the Electric Water Pump, SAE 2004-32-0084.

6. Karassik, I. J., et al. (2001), pump handbook, 3rd edition, McGraw-Hill.

7. McCabe, W. L., Smith J. C. and Harriott, P. (1993), Unit Operations of Chemical Engineering, Fifth Edition, McGraw Hill International, Singapore

8. Van Basshuysen, R. and Schafer, F. (2007), Modern Engine Technology from A to Z, SAE International, ISBN: 978-0-7680-1705-2. 
9. Robert, D. and Chalgren, Jr., (2004). Thermal Comfort and Engine Warm-Up Optimization of a Low-Flow Advanced Thermal Management System, SAE Technical Paper 2004-01-0047.

10. Haipeng, L. and Figliola, R. S., (2004). Optimization of an Automotive Cooling System Based on Exergy Analysis, SAE Technical Paper 2004-01-3541.

11. Kluger, M. and Harris, J., (2007). Fuel Economy Benefits of Electric and Hydraulic Off Engine Accessories" SAE Technical Paper 2007-01-0268.

12. AP, N. S. and Golm, N. C., (1997). New Concept of Engine Cooling System (Newcool), SAE Technical Paper SAE Technical Paper 971775.

13. Choukroun, A. and Chanfreau, Matthieu, (2001). Automatic Control of Electronic Actuators for an Optimized Engine Cooling Thermal Management, SAE Technical Paper SAE Technical Paper 2001-01-1758.

14. Wagner, J. R., Ghone M. C., Dawson, D. W. and Marotta, E. E. (2002). Coolant Flow Control Strategies for Automotive Thermal Management Systems " SAE Technical Paper 2002-01-0713.

15. Davies Craig Catalog (2010), Electric Water Pump Selection Guide. 


\section{NOMENCLATURE}

$\begin{array}{ll}\mathrm{N}_{\mathrm{s}} & \text { the specific engine speed in rpm; } \\ \mathrm{N} & \text { the pump rotational speed in rpm; } \\ \mathrm{H} & \text { the discharge head; } \\ \mathrm{Q} & \text { the flow rate in gram per minutes; } \\ \Psi & \text { the head coefficient or shut off constant; } \\ \mathrm{g} & \text { the gravity acceleration; } \\ \eta_{\mathrm{h}} & \text { the hydraulic efficiency; } \\ \mathrm{C}_{\mathrm{m} 3} & \text { the meridional velocity; } \\ \mathrm{U}_{2} & \text { the impeller peripheral speed; } \\ \beta_{2} & \text { the discharge vane angle; } \\ \mathrm{C}_{\mathrm{u} 3} & \text { theoretical peripheral velocity; } \\ \mathrm{C}_{\mathrm{u} 3}^{\prime} & \text { the actual fluid peripheral velocity; } \\ \mathrm{Z} & \text { the number of blades; } \\ \mu & \text { the slip factor; }\end{array}$

Subscripts

s

specific;

$\mathrm{h}$

hydraulic; 
m3

meridional;

u3

peripheral velocity;

Abbreviations

ICE

NEDC ECE 15 EUDC

RPM

FEAD

$\mathrm{A} / \mathrm{F}$

CR

VVT
Internal Combustion Engine

New European Driving Cycle 'ECE 15' Extra-Urban Driving

Cycle

Revolution Per Minute

Front End Accessory Drive

Air/Fuel ratio;

Compression Ratio;

Variable Valve Timing; 